\title{
Comments on "Solubility of Ethyl Maltol in Aqueous Ethanol Mixtures" (Liu, B.-S.; Liu, R.-J.; Hu, Y.-Q.; Hu, Q.-F. J. Chem. Eng. Data 2008, 53, 2712-2714)
}

Abolghasem Jouyban*, ${ }^{* \dagger}$ and William Eugene Acree, Jr.*

Faculty of Pharmacy and Drug Applied Research Center, Tabriz University (Medical Sciences), Tabriz 51664, Iran, Department of Chemistry, University of North Texas, Denton, Texas 76203-5070

\section{Introduction}

In a recent paper in this journal, Liu et al. ${ }^{1}$ reported the experimental solubilities of ethyl maltol in binary mixtures of ethanol + water at various temperatures. The authors correlated the experimental mole fraction solubilities using a fourth-order polynomial equation derived ${ }^{2}$ from the CNIBS/R-K model ${ }^{3}$ and evaluated the fitness of the model employing root-meansquare deviations (RMSDs). Liu et al. ${ }^{1}$ employed the model at a fixed temperature which is expressed as

$$
\ln x_{\mathrm{m}}=f_{1} \ln x_{1}+f_{2} \ln x_{2}+f_{1} f_{2} \sum_{i=0}^{2} S_{i}\left(f_{1}-f_{2}\right)^{i}
$$

where $x_{\mathrm{m}}, x_{1}$, and $x_{2}$ are the numerical values of the solubility of the solute in the mixture and solvents 1 and 2, respectively; $f_{1}$ and $f_{2}$ are the volume (mass or mole) fractions of solvents 1 and 2 in the mixture in the absence of the solute; and $S_{i}$ represent the model constants. The model could be rearranged to eq 2 by replacing $f_{2}$ with $1-f_{1}$ and further simplified as ${ }^{2}$

$$
\begin{aligned}
& \ln x_{\mathrm{m}}=\ln x_{2}+\left(\ln x_{1}-\ln x_{2}+S_{0}-S_{1}+S_{2}\right) f_{1}+ \\
& \quad\left(-S_{0}+3 S_{1}-5 S_{2}\right) f_{1}^{2}+\left(-2 S_{1}+8 S_{2}\right) f_{1}^{3}+\left(-4 S_{2}\right) f_{1}^{4}
\end{aligned}
$$

or

$$
\ln x_{\mathrm{m}}=B_{0}+B_{1} f_{1}+B_{2} f_{1}^{2}+B_{3} f_{1}^{3}+B_{4} f_{1}^{4}
$$

From a theoretical viewpoint, $B_{0}=\ln x_{2}, B_{1}=\ln x_{1}-\ln x_{2}+$ $S_{0}-S_{1}+S_{2}$, etc.; however, the fitted coefficients do not exactly match these values, and this causes slightly different errors in the calculations. As an example, the fitted eq 1 to the experimental data of ethyl maltol at $298.15 \mathrm{~K}$ yields

$$
\begin{aligned}
& \ln x_{\mathrm{m}}=-2.528 f_{1}- 6.075 f_{2}+6.442 f_{1} f_{2}- \\
& 3.922 f_{1} f_{2}\left(f_{1}-f_{2}\right)+3.780 f_{1} f_{2}\left(f_{1}-f_{2}\right)^{2}
\end{aligned}
$$

and the corresponding polynomial reported by Liu et al. ${ }^{1}$ is

\footnotetext{
* Author to whom correspondence should be addressed. E-mail: ajouyban@ hotmail.com. Fax: +98 4113363231.

Faculty of Pharmacy and Drug Applied Research Center.

$\doteqdot$ University of North Texas.
}

$$
\begin{aligned}
& \ln x_{\mathrm{m}}=-6.0626+ 17.5415 f_{1}- \\
& 36.5826 f_{1}^{2}+37.3772 f_{1}^{3}-14.7977 f_{1}^{4}
\end{aligned}
$$

Substituting the constant values of eq 4 into eq 2 yields

$$
\begin{aligned}
\ln x_{\mathrm{m}}=-6.0748+ & 17.6906 f_{1}- \\
& 37.1080 f_{1}^{2}+38.0840 f_{1}^{3}-15.1200 f_{1}^{4}
\end{aligned}
$$

Normally the calculated equation coefficients are much closer. Irrespective of the reason why the equation coefficients are slightly different, there is no significant difference between accuracies of eqs 4 to 6 .

The aim of this communication is to point out several capabilities of the CNIBS/R-K model (renamed as the Jouyban-Acree model) that journal readers may not have seen. The basic model does contain provisions for representing both the effects of solvent composition and temperature on the solubility of solutes ${ }^{4}$

$$
\ln x_{\mathrm{m}, T}=f_{1} \ln x_{1, T}+f_{2} \ln x_{2, T}+f_{1} f_{2} \sum_{i=0}^{2} \frac{J_{i}\left(f_{1}-f_{2}\right)^{i}}{T}
$$

where $x_{\mathrm{m}, T}, x_{1, T}$, and $x_{2, T}$ are the numerical values of the solubility of the solute in the mixture and solvents 1 and 2 at temperature $T$, respectively, and $J_{i}$ represent the model constants. The $J_{i}$ terms could be calculated by regressing $\left(\ln x_{\mathrm{m}, T}-f_{1} \ln x_{1, T}-f_{2} \ln x_{2, T}\right)$ against $\left(f_{1} f_{2}\right) / T,\left[f_{1} f_{2}\left(f_{1}-f_{2}\right)\right] / T$, and $\left[f_{1} f_{2}\left(f_{1}-f_{2}\right)^{2}\right] / T$ by a no intercept least-squares analysis. The model could be trained using the solubility of a solute in binary solvents at $298.15 \mathrm{~K}$, and then the solubility at higher and lower temperatures could be predicted employing the experimental values of $x_{1, T}$ and $x_{2, T}$ at the temperature of interest. Alternatively, the solubility of various solutes in ethanol + water mixtures at various temperatures could be predicted employing $x_{1, T}$ and $x_{2, T}$ values by using a previously trained Jouyban-Acree model. ${ }^{5}$

The Jouyban-Acree model has provided accurate predictions for the solubility of drugs in mixed solvents at various temperatures. Considering this capability, we have fitted the model to the solubility of ethyl maltol in ethanol + water mixtures at various temperatures and calculated the model constants along with the mean deviation (MD) values defined by

$$
\mathrm{MD}=\frac{\sum\left(\frac{\left|x_{\mathrm{m}, \mathrm{Calc}}-x_{\mathrm{m}, \mathrm{Obs}}\right|}{x_{\mathrm{m}, \mathrm{Obs}}}\right)}{N}
$$


Table 1. Mean Deviation (MD \%) for Various Equations Investigated in This Work for Back-Calculated and Predicted Solubilities Before * and After ** Corrections on the Original Article $^{1,13}$

\begin{tabular}{lcccccc}
\hline & \multicolumn{3}{c}{ back-calculated } & & \multicolumn{2}{c}{ predicted } \\
\cline { 2 - 4 } \cline { 6 - 7 }$T(\mathrm{~K})$ & eq 1 or 2 & $\begin{array}{c}\text { eq } 3 \text { with the } \\
\text { reported } B_{0} \\
\text { to } B_{4} \text { terms }\end{array}$ & eq 9 & $\begin{array}{c}\text { eq } 9 \text { trained with } \\
\text { data at } \\
2{ }^{\circ} \mathrm{C}\end{array}$ & eq 10 \\
\hline $293.15^{*}$ & 6.4 & 17.3 & 55.2 & 28.1 & 17.3 \\
$293.15^{* *}$ & 1.6 & 1.8 & 36.5 & 10.5 & 10.6 \\
298.15 & 0.8 & 0.9 & 21.1 & - & 15.5 \\
303.15 & 1.3 & 1.3 & 10.9 & 7.3 & 20.7 \\
308.15 & 0.5 & 0.6 & 4.8 & 12.7 & 25.0 \\
313.15 & 2.1 & 2.1 & 6.4 & 17.3 & 26.8 \\
318.15 & 2.3 & 2.2 & 10.5 & 19.5 & 28.5 \\
323.15 & 3.2 & 3.2 & 12.8 & 20.6 & 29.6 \\
328.15 & 3.4 & 3.5 & 13.7 & 21.2 & 30.3 \\
333.15 & 4.0 & 4.1 & 12.7 & 20.4 & 27.7 \\
Overall MD \% & 2.1 & 2.2 & 14.4 & 16.2 & 23.9
\end{tabular}

in which $N$ is the number of data points in each set. The $100 \cdot \mathrm{MD}$ values could be directly compared with the experimentally obtained relative standard deviation (RSD) values for assessing the accuracy of a model for representing the data. The fitted model using all data points was

$$
\begin{gathered}
\ln x_{\mathrm{m}, T}=f_{1} \ln x_{1, T}+f_{2} \ln x_{2, T}+2194.927\left[\frac{f_{1} f_{2}}{T}\right]+ \\
2066.349\left[\frac{f_{1} f_{2}\left(f_{1}-f_{2}\right)}{T}\right]+1916.914\left[\frac{f_{1} f_{2}\left(f_{1}-f_{2}\right)^{2}}{T}\right]
\end{gathered}
$$

Equation 9 is a statistically significant correlation $(F=766$, $p<0.0005)$ and mathematically describes the solubilities at various temperatures using a single model. It enables one to predict the solubilities at other temperatures and solvent compositions using interpolation/extrapolation techniques. The MD from this calculation was $14.4 \%(N=81)$. Details of MDs at the different temperatures are listed in Table 1 in which the MDs are the same for eqs 1 to 3 . It is also possible to train the Jouyban-Acree model employing the solubility data at 298.15 $\mathrm{K}$ and then predict the solubilities at other temperatures. The calculated MD for the predicted solubilities at temperatures other than $298.15 \mathrm{~K}$ was $16.2 \%(N=72)$.

Alternatively, one may use a generally trained version of the Jouyban-Acree model for predicting the solubility of ethyl maltol at various temperatures. The trained version of the model for predicting the solubility of solutes in ethanol + water mixtures at various temperatures was $^{5}$

$$
\begin{gathered}
\ln x_{\mathrm{m}, T}=f_{1} \ln x_{1, T}+f_{2} \ln x_{2, T}+1667.856\left[\frac{f_{1} f_{2}}{T}\right]+ \\
1117.347\left[\frac{f_{1} f_{2}\left(f_{1}-f_{2}\right)}{T}\right]+447.426\left[\frac{f_{1} f_{2}\left(f_{1}-f_{2}\right)^{2}}{T}\right]
\end{gathered}
$$

and the obtained MD for the predicted solubilities was $23.9 \%$. It should be noted that none of the ethyl maltol data were used in the training process of eq 10. However, they provided reasonably accurate predictions employing just two experimental data points in monosolvents at each temperature. The acceptable prediction error range should be defined concerning the experimental RSD values. Ideally an error level less than the experiment RSD value is preferred. From a practical point-ofview, an error level of $\sim 30 \%$ has been suggested as an acceptable error range for fitted solubility data, ${ }^{6,7}$ for many applications.

The main advantages that the Jouyban-Acree model have over the polynomial model for representing the solubility of solutes in binary solvent mixtures are: 1) a uniform mathematical representation of solubility and other physicochemical properties; 2) the calculated equation coefficients for binary solvent mixtures can be combined to estimate solute solubility in ternary and higher-order multicomponent systems; ${ }^{8}$ and (3) the model contains provisions for correlating experimental solubility as a function of both temperature and solvent composition. For illustrational purposes, we have assumed a rather simple temperature dependence of $S_{i} / T$ which has been successful in correlating densities, ${ }^{9}$ surface tensions, ${ }^{10}$ acid dissociation constants, ${ }^{11}$ and viscosity ${ }^{12}$ as a function of temperature. There is no reason that one cannot assume a more complex temperature variation such as $S_{i}+S_{i}^{\prime} / T$ if need be. In using the

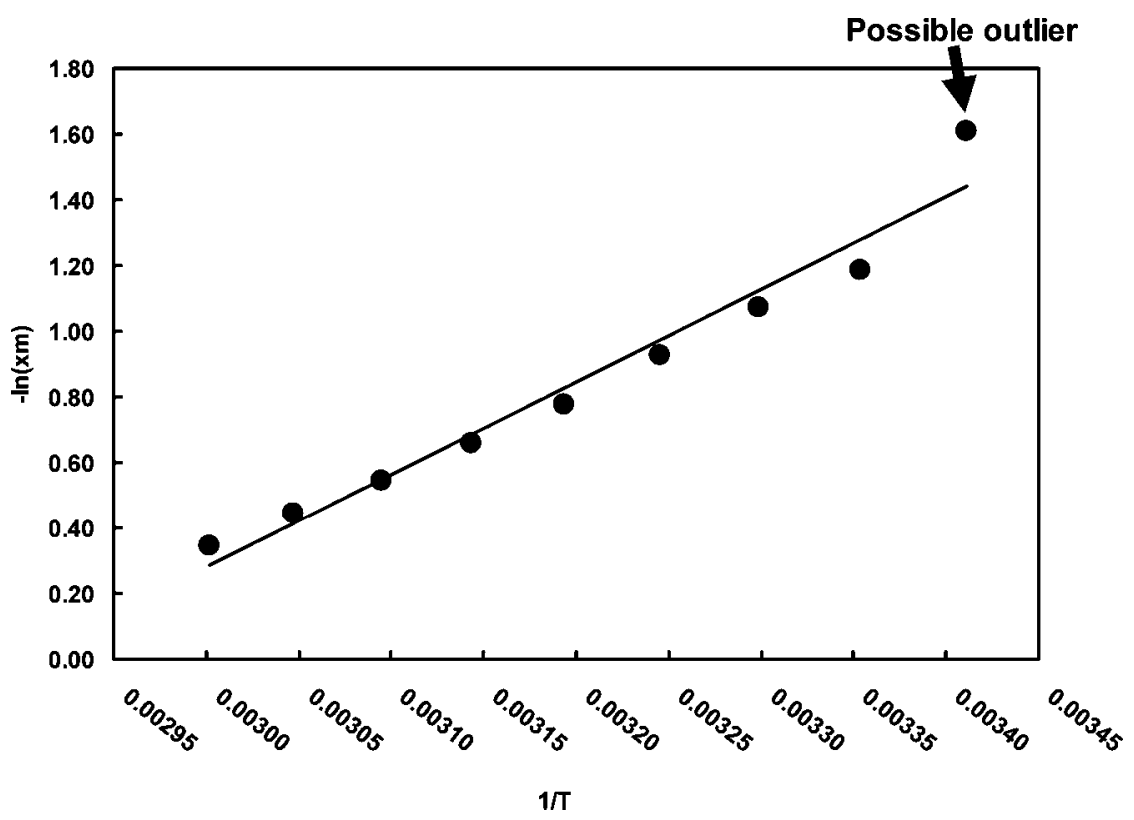

Figure 1. van't Hoff plot of solubility of ethyl maltol at $f_{\text {ethanol }}=0.4771$ to detect a possible outlier. 
Jouyban-Acree model as a mathematical representation, we encourage users to consider a temperature-dependent form for the equation coefficients (such as $S_{i} / T$ or $S_{i}+S_{i}^{\prime} / T$ ), as it may be possible to include temperature and composition dependence into a single mathematical correlation.

The basic model has the capability of providing a generally trained model, such as eq 10 to predict the unmeasured solubilities, and can be used to detect possible outliers in experimental data sets for redetermination. As an example, the solubility data of ethyl maltol in $0.4771 \mathrm{~mol}$ fraction of ethanol at $293.15 \mathrm{~K}^{1}$ produced the highest deviation from the predicted solubility. Careful examination of the reported data reveals that this experimental value is likely an experimental and/or typographical error. If fact, the equation coefficients reported in the manuscript do not reproduce the experimental ethyl maltol solubility data that are reported in Table 1 of the original article for $293.15 \mathrm{~K}$. Using the authors' equation coefficients, the calculated mole fraction solubility of ethyl maltol at an ethanol mole fraction of 0.4771 should be 0.0464 . The van't Hoff plot (see Figure 1) suggests that this datum is likely a mistyped data. There appears to be a duplicate entry of ethyl maltol mole fraction solubility of 0.0246 in Table 1 for ethanol mole fractions of 0.2811 and 0.4471 . The authors' reported deviations between experimental and back-calculated values are wrong. The deviations that are given in the Table 1 of the article are $\left(x_{\mathrm{m}, \mathrm{Obs}}-\right.$ $\left.x_{\mathrm{m}, \mathrm{Calc}}\right)$, and not $10^{3}\left(x_{\mathrm{m}, \mathrm{Obs}}-x_{\mathrm{m}, \mathrm{Calc}}\right)$ as the column headings state.

During the review process of this commentary, Liu et al. revised the experimental data, and by including the corrected data, ${ }^{13}$ the MD values at $293.15 \mathrm{~K}$ dramatically decreased for all numerical methods discussed above and also MD of all temperatures for the back-calculated data by eq 9 , since the outlier points could change the numerical values of the model. This observation is more evidence for the advantages of the proposed models, especially previously trained models to estimate the unmeasured solubilities and also to detect possible outliers.

\section{Literature Cited}

(1) Liu, B. S.; Liu, R. J.; Hu, Y. Q.; Hu, Q. F. Solubility of Ethyl Maltol in Aqueous Ethanol Mixtures. J. Chem. Eng. Data 2008, 53, 27122714.

(2) Barzegar-Jalali, M.; Jouyban-Gharamaleki, A. A General Model from Theoretical Cosolvency Models. Int. J. Pharm. 1997, 152, 247-250.

(3) Acree, W. E., Jr. Mathematical Representation of Thermodynamic Properties. Part II. Derivation of the Combined Nearly Ideal Binary Solvent (NIBS)/Redlich-Kister Mathematical Representation from a Two-Body and Three-Body Interactional Mixing Model. Thermochim. Acta 1992, 198, 71-79.

(4) Jouyban-Gharamaleki, A; Acree, W. E., Jr. Comparison of Models for Describing Multiple Peaks in Solubility Profiles. Int. J. Pharm. 1998, 167, 177-182.

(5) Jouyban, A.; Acree, W. E., Jr. In Silico Prediction of Drug Solubility in Water-Ethanol Mixtures Using Jouyban-Acree Model. J. Pharm. Pharm. Sci. 2006, 9, 262-269.

(6) Reillo, A.; Cordoba, M.; Escalera, B.; Selles, E.; Cordoba, M., Jr. Prediction of Sulfamethiazole Solubility in Dioxane-Water Mixtures. Pharmazie 1995, 50, 472-475.

(7) Beerbower, A.; Wu, P. L.; Martin, A. Expanded Solubility Parameter Approach 1. Naphthalene and Benzoic Acid in Individual Solvents. J. Pharm. Sci. 1984, 73, 179-188.

(8) Jouyban-Gharamaleki, A.; Clark, B. J; Acree, W. E., Jr. Models to Predict Solubility in Ternary Solvents Based on Sub-Binary Experimental Data. Chem. Pharm. Bull. 2000, 48, 1866-1871.

(9) Jouyban, A.; Fathi-Azarbayjani, A.; Khoubnasabjafari, M.; Acree, W. E., Jr. Mathematical Representation of the Density of Liquid Mixtures at Various Temperatures using Jouyban-Acree Model. Indian J. Chem. A 2005, 44, 1553-1560.

(10) Jouyban, A.; Fathi-Azarbayjani, A.; Khoubnasabjafari, M.; Acree, W. E., Jr. Surface Tension Calculation of Mixed Solvents with Respect to Solvent Composition and Temperature by Using the Jouyban-Acree Model. Chem. Pharm. Bull. 2004, 52, 1219-1222.

(11) Jouyban, A.; Soltani, S.; Chan, H. K.; Acree, W. E., Jr. Modeling Acid Dissociation Constant of Analytes in Binary Solvents at Various Temperatures Using the Jouyban-Acree Model. Thermochim. Acta 2005, 428, 119-123.

(12) Jouyban, A.; Vaez-Gharamaleki, Z.; Fekari, Z.; Acree, W. E., Jr. Calculation of the Viscosity of Binary Liquids at Various Temperatures using the Jouyban-Acree Model. Chem. Pharm. Bull. 2005, 53, 519523 .

(13) Liu, B.-S.; Liu, R.-J.; Hu, Y.-Q.; Hu, Q.-F. Corrections on Solubility of Ethyl Maltol in Aqueous Ethanol Mixtures. J. Chem. Eng. Data 2009, 54, 1171.

Received for review October 27, 2008. Accepted February 5, 2009.

JE800798D 